\title{
The Exploration and Practice of Research-Based Teaching Method in the Course of Management
}

\begin{abstract}
Jian Wen*
School of Economics and Management, Beijing University of Posts and Telecommunications, Beijing, China

${ }^{*}$ Corresponding author

ABSTRACT

At present, many universities have some problems in the course of management, such as the outmoded content of teaching materials, the disconnection between theory and practice, and the single way of course assessment, which results in the lack of students' passive learning and active participation, which is not conducive to the training of students' management ability and management thinking. With reference to the theory of research-based teaching, the author of this paper has been actively exploring and practicing the research-based teaching methods of management course for several years, hoping to communicate with colleagues through this article, in order to promote the in-depth research and practice of research-based teaching in China.
\end{abstract}

Keywords: Research-based Teaching, Management, Innovative talents

\section{《管理学》课程研究性教学法的探索与实践}

\author{
温健*
}

北京邮电大学经济管理学院, 北京, 中国

“通讯作者

\section{中文摘要}

目前很多高校在《管理学》课程教学中, 存在教材内容陈旧、理论与实践脱节、课程考核方式单一等 问题, 造成学生被动的学习、主动参与性不够, 这不利于对于学生的管理能力和管理思维的训练。借 鉴研究性教学理论, 本文作者几年来一直在积极探索和实践《管理学》课程的研究性教学方法, 希望 通过本文同各位同行进行交流，以期推进研究性教学在我国的深入研究与实践。

关键词: 研究性教学; 管理学; 创新人才

\section{1. 引言}

在当今依靠创新求发展的时代, 要求大学毕业生必 须具有较高的创新精神和创新能力。肩负人才培养重 任的高等学校, 正在积极学习和吸收国外大学的研究性 教学方法, 积极开展各类创新人才培养模式的探讨, 比 如清华大学在 “学生研究训练” 中由知名教授为本科 生授课; 浙江大学增设综合性、研究型、项目化课程, 讨论式小班化教学, 实施大学科研训练计划等 ${ }^{[1]}$ 。

目前高校研究性教学的开展主要是通过学生参加 竞赛活动、参与科研项目等方式进行 ${ }^{[2]}$, 而从 “第一课 堂” 教学的角度来探究研究性教学的还较少。本文作者 在学习借鉴已有研究性教学理论和实践的基础上, 结合
《管理学》课程的特点和管理学科人才培养目标, 构建 了《管理学》研究性教学模式, 并在多轮的课堂教学中 进行实践, 收到了良好的效果。

\section{2. 《管理学》课程开展研究性教学的意义}

《管理学》是一门研究管理活动规律的知识体系, 是一门实践性很强的学科。目前我国高校在《管理学》 课程的建设和教学中, 普遍存在着教材内容陈旧、灌输 式教学方式、理论与实践脱节、课程考核方式单一等问 题, 造成学生被动的学习、主动参与性不够, 不利于对 于学生的管理能力和管理思维的训练, 不利于学生创新 性解决问题能力的培养。 
经济全球化和科学技术的突飞猛进，市场竞争的日 趋激烈, 引发了对高素质人才需求的竞争, 不仅是技术 人才, 也包括管理人才, 技术和管理是推动社会发展的 “两个车轮”，缺一不可。没有先进的管理，技术创新 也很难产生和发挥出应有的作用, 管理的重要性已被越 来越多的有识之士所认识。但是目前我国的管理教育理 念和方法还相对落后, 还不能适应对于高层次创新管理 人才培养的需要, 因此改革大学课程教学已成为当代最 为紧迫的任务, 这也给 《管理学》的教学带来了新的挑 战。引入研究性教学将对更新《管理学》教学理念、改 进教学模式产生积极的影响。

\section{3. 《管理学》课程研究性教学研究现状}

\section{1. 研究性教学的研究视角}

教育部在《关于进一步加强高等学校本科教学工作 的若干意见》中明确提出, 大学 “要积极推动研究性教 学, 提高大学生的创新能力” ${ }^{[2]}$ 。从此, 对于研究性教 学的研究, 包括工学、教育学、管理学、经济学等多个 学科在我国高校得到了日益重视。其中开展的较早且在 全国有较大影响的是南京大学的卢德馨教授, 卢教授在 大学生基础物理课的教学中, 成功地实施了多种研究性 教学模式, 取得了重要成果, 多名本科生在国际一流期 刊发表学术论文。除此之外, 南京大学的梁林梅、刘永 贵、桑新民, 北京交通大学的阮秋琦, 中山大学的王金 发也都将研究性教学法付诸于教学实践。

目前高校研究性教学的开展主要是通过学生参加 竞赛活动、参与科研项目等方式进行 ${ }^{[3]}$, 事实上能够参加 竞赛和参与教师科研项目的毕竟仅是少数学生, 更多的 学生被排除在探究之外。因此从 “第一课堂” 教学的 角度来探究研究性教学, 具有更加现实的意义。

本文的研究正是从课程教学的视角, 对《管理学》 课程研究性教学进行探索与实践总结, 希望对创新人才 的培养能有所贡献。

\section{2. 国内《管理学》课程研究性教学的研究 现状}

近年来国内许多学者对《管理学》课程的研究性教 学法进行了较深入的研究。㚞建民指出教师应加强教材 建设, 采用 “案例教学法” 等来提高教学质量 ${ }^{[4]}$ 。刘传 宏认为, 要强化学生主体的地位, 着重培养和提高学生 运用所学解决实际问题的能力和人际交往的能力 ${ }^{[5]}$ 。北 京交通大学张明玉老师在《管理学》课程中提出了 “图 钉式” 教学法, 针对初学者、优秀学生, 分层次培养多 元化人才 ${ }^{[6]}$ 。王华强、高映红基于当前我国高校《管理 学》多元化教学的新形势和新背景, 从学生、教师和学 校三个角度研究提出了《管理学》课程教学改革的思路
和方法 ${ }^{[7]}$ 。这些研究从 《管理学》的教学理念、培养 目标、教学内容、教学方法等方面对新形势下高素质创 新人才的培养进行了阐述。

\section{4. 《管理学》课程研究性教学模式及特点}

\section{1. 《管理学》课程研究性教学模式}

在借鉴现有《管理学》课程研究性教学成熟模式的 基础上, 结合课题组教师的课程实践, 我们构建的《管 理学》研究性教学的模式如图1所示。其含义是：以研 究性教学为指导思想, 建立以 “以学生为中心” 的原则, 明确教师定位, 创新教学内容和多元化的教学方法体 系, 注重学生能力的考核, 实现具有创新精神和能力的 人才培养目标。

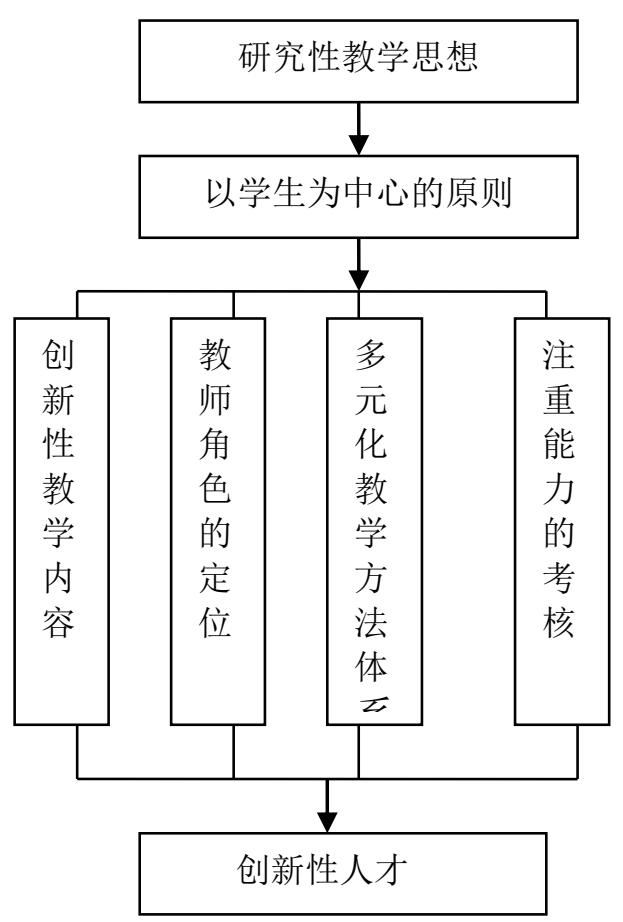

图 1 《管理学》研究性教学模式 


\section{2. 特点}

\subsection{1. 建立以学生为中心的原则}

传统的教学是以教师为中心, 教师上课满堂灌, 教 师讲什么学生学什么, 学生处于被动地位, 更多的是对 知识的记忆背诵, 没能探索知识、理论的来龙去脉, 不 能根据自己兴趣去进行研究, 因为学生更多成绩主要就 是期中期末考试, 这样由于缺乏研究性学习, 也就失去 了培养学生研究能力的机会。现在的教育理念要求教师 以学生为中心, 充分发挥学生的学习和探索的主动性, 变过去的知识传授者为学生研究性学习的引路人。

\subsection{2. 创新教学内容}

课堂中教材知识内容的讲解固然重要, 但仅做到这 一点还不够。教师还要结合自己科研的成果, 向学生介 绍如何进行知识创新, 包括如何选择研究课题, 如何选 择科研路线等, 培养学生的科研能力。另外, 还应向学 生介绍本学科的前沿发展和研究动向, 引导学生积极主 动关注学科发展, 培养其阅读专业期刊和文献的习惯和 能力。同时鼓励学生根据自己的兴趣选择题目进行研 究, 培养其理论联系实际以及创新研究的能力。

\section{2. 3. 多元化的教学方法}

\section{(1) 开篇案例}

以问题为导向的教学方法, 可以使学生带着问题去 学, 满足 “心灵深处” 的需要, 变传统的 “要我学” 为” 我要学”。

为此, 我们在教学中每章的开始都加入了开篇案 例, 案例涉及该章的主要理论和方法, 使得学生充分看 到了理论知识的价值, 最大限度地激发学生的学习热 情。比如在给学生讲授 “计划” 职能前, 我们给学生讲 “世界500强企业沃尔玛的成功故事”，说明它的 “农 村包围城市” 战略是如何促使它成功的; 又比如, 美国 西南航空公司做为一家中小型公司是如何通过实施 “低成本战略” 而在竞争激烈的美国航空业站稳脚跟 的, 使学生认识到战略对于企业成功的重要性, 促使其 有更高的积极性去研究和学习如何制定一个好的战略。

(2) 案例分析

案例分析教学法可以培养学生理论联系实际的能 力, 收集资料, 整理分析数据, 形成和表达自己观点的 能力。特别是《管理学》是一门实践性很强的学科, 案例分析法有着非常重要的作用。

在案例讨论中，教师一方面要鼓励学生的积极参 与, 另一方面要把控讨论, 促成学生紧紧围绕案例讨论 的主题形成热烈的讨论氛围。

(3) 课程作业
所谓课程作业, 是一种学生以小组的形式完成的研 究题目, 它面向全体同学, 每个人都必须参加一个小组, 达到促使学生进行能力训练的目的。具体做法是：教师 事先准备好数十个研究题目, 在开学第一次上课时布置 给学生, 让学生组成 $5^{\sim} 7$ 人研究小组, 选择感兴趣的题 目, 然后通过小组成员的分工合作，通过对资料的收集、 整理和分析, 最终完成研究题目。

课程作业的完成, 加深了学生对于知识的理解, 培 养了其运用知识解决实际问题的能力, 同时使其受到了 在论文写作方面的训练。

(4) 提问

为了加深学生对于知识的理解, 教学中教师还可以 使用设问、反问等方式。还可以鼓励学生自己提出有价 值的提问，促进学生对于知识的深入理解。

(5) 演讲

在《管理学》教学中, 我们每一章都有一个小组讨 论案例, 学生在课前以小组为单位完成, 然后由小组代 表或者是各个同学按照分工在课堂上演讲, 其他同学进 行补充, 从而达到锻炼学生口头表达能力的目的。

(6) 研究论文

在课程教学中, 我们根据学生的学习成绩以及个人 兴趣, 每班选择了大概 3 名同学进行研究论文的写作 (也 可以是几个人组成小组), 学生自己选择研究领域和具 体题目, 教师给予必要的指导。从实施的效果来看, 相 当多的学生积极性很高, 而且完成的论文质量也令教师 满意, 学生的科研能力也得到开发。

(7) 专家讲座

邀请校内外的专家做专题讲座，可以加深学生对于 知识的理解，分享别人的实践经验。也可以邀请有关行 政部门工作者前来就一些政策性、实践性强的内容进行 专题讲授。

\subsection{4. 注重过程的考核}

传统的考核注重结果的考核，方式单一，主要采用 期中、期末考试的形式, 容易出现学生平时记笔记、考 前背笔记、考后扔笔记的现象, 学生只是应付考试, 不 利于学生能力的培养。

研究性教学注重的是过程的考核, 从课堂表现、案 例讨论、演讲、课程作业、期中和期末考试等多方面进 行考核，可适当加大平时成绩在总评中的比例，减少期 中和期末的比例。比如课堂表现 (5\%)、案例讨论 (15\%)、 演讲 (10\%)、课程作业（20\%）、期中和期末考试（50\%）。

\section{5. 结束语}

研究性教学是一种以学生为中心的现代教学模式, 它将学生能力的培养放在首位, 通过实施多种形式的研 究性教学方式, 不仅使学生对于教学内容产生兴趣, 而 且能够做到积极主动地学习, 通过学中用、用中学、研 究中学, 加深学生对于知识和理论产生来源的认识, 对 
于他们将来进行知识创新奠定了坚实的方法论和能力 的基础。同时也培养了他们团队合作的技能, 以及敢于 直面困难, 坚持不解, 奋发向上的精神和能力, 这将是 他们今后进一步深造学习和适应工作的宝贵财富。

\section{致谢}

本文为北京邮电大学校级教改项目 《《管理学》课 程研究性教学法探索与实践》的阶段性成果之一。

\section{REFERENCES}

[1] Xiao-dong XV, Xiang-dong FENG, Research and practice of research-based teaching mode for science and engineering undergraduates, China University Teaching, 2008(11)

[2] Department of Higher Education, Ministry of Education of the People's Republic of China, Research and Demonstration of Research-based Learning and Innovation Ability Training,

Higher Education Press, Beijing, 2010.

[3] Fan MENG, Research on the theory and practice of research-based teaching for Undergraduates: Taking the teaching reform practice of Professor Jianjun JIANG of Huazhong University of Science and Technology as an example, Master's thesis, Huazhong University of Science and Technology, Wuhan, 2007(6)

[4] Jian-min FAN, The exploration of the teaching reform in the course of management, Journal of Yangzhou University, 2004(1)

[5] Chuan-hong LIU, Reform and construction of management course in colleges and universities, Henan Education, 2006(4)

[6] Ming-yu ZHANG, Reform and implementation of research-based teaching in management, in: Yan-ping LIU, Zhen-ji ZHANG (Eds.), Research on the Training Mode of Economic Management Talents from Multiple Perspectives, Publishing House of Electronics Industry, Beijing, 2009, pp.166-170.

[7] Hua-qiang WANG, Ying-hong GAO, A probe into the teaching reform of the course on management science in new situation, Higher Education Forum, 2007(6)

[8] Hai-yong LI, Research on Research-based Learning and Cultivation of Innovative Thinking, Xi'an Jiaotong University Press, Xi'an, 2017.
[9] Hong-xing HU, Research on the Implementation of Research-based Learning Course, China Social Sciences Press, Beijing, 2017.

[10] Yan YANG, Zhou CHUN, Sen SHEN, Exploring the teaching reform of "Basis of Management Science" course, Education Teaching Forum, 2018 (6) 